\title{
Kombinasi terapi musik instrumental dan self hypnosis efektif menurunkan tekanan darah klien hipertensi
}

\author{
Edi Purnomo ${ }^{1 *}$ Zulkipli², Zulhaini Sartika A. Pulungan $^{3}$ \\ ${ }^{1}$ Jurusan Keperawatan Politeknik Kesehatan Kementerian Kesehatan Mamuju \\ ${ }^{2}$ Program Studi Keperawatan Stikes Andini Persada Mamuju
}

\section{Keywords :}

hypertension, instrumental music, self hypnosis

\section{Kontak :}

Edi Purnomo

Email : edipurnomo041077@gmail.com Jurusan Keperawatan Politeknik Kesehatan Kementerian Kesehatan Mamuju

Vol 2 No 1 September 2019

DOI: https://doi.org/10.31605/jhealt.v2i1

(C)2018J-Healt

ini adalah artikel dengan akses terbuka

dibawah licenci CC BY-NC-4.0

https://creativecommons.org/licenses/by-nc/4.0/

\begin{abstract}
Hypertension is a condition that often occurs at the age of more than 30 years, and this incidence will increase in the elderly (age 50 years). One of the non-pharmacological therapies that develop today is hypnotherapy. The combination of instrumental music and self hypnosis $i$ an alternative choice to achieve a relaxed state that will reduce stress and depression in hypertensive clients who can lower blood pressure. This study aims to determine the effectiveness of a combination of instrumental and self hypnosis music therapy to decrease blood pressure of hypertensive clients in the work area of Puskesmas Rangas Kabupaten Mamuju. This research is a pre experiment research with one group pretest-posttest design. The study population was hypertensive patients who visited Puskesmas Rangas Kab. Mamuju. The sample size is 30 people with sampling technique using purposive sampling. The results showed a significant difference in systolic blood pressure before and after instrumental and self hypnosis $(p=0.0005)$ and a significant difference in diastolic blood pressure before and after instrumental and self hypnosis $(p=0.0005)$. The combination of instrumental music therapy and self hypnosis effectively lowers the blood pressure of hypertensive clients. Researchers recommend to nurse practitioners to apply this therapy to lower blood pressure in clients who have hypertension.
\end{abstract}




\section{PENDAHULUAN}

Hipertensi adalah salah satu penyebab utama mortalitas dan morbiditas di Indonesia, sehingga tatalaksana penyakit ini merupakan intervensi yang sangat umum dilakukan diberbagai tingkat fasilitas kesehatan (Soenarta dkk., 2015). DataWorld Health Organization (WHO) tahun 2011 menunjukkan satu milyar orang di dunia menderita hipertensi, dua per tiga diantaranya berada dinegara berkembang yang berpenghasilan rendah sampai sedang. Prevalensi hipertensi akan terus meningkat tajam dan diprediksi pada tahun 2025 sebanyak $29 \%$ orang dewasa di seluruh dunia terkena hipertensi. Hipertensi telah mengakibatkan kematian sekitar 8 juta orang setiap tahun, dimana 1,5 juta kematian terjadi di Asia Tenggara yang $1 / 3$ populasinya menderita hipertensi, sehingga dapat menyebabkan peningkatan beban biaya kesehatan (Kemenkes RI, 2017).

Hipertensi merupakan suatu penyakit kronis yang sering disebut silent killer karena pada umumnya pasien tidak mengetahui bahwa mereka menderitapenyakit hipertensi sebelum memeriksakan tekanan darahnya. Penderita hipertensi umumnya juga tidak mengalami suatu tanda atau gejala sebelum terjadikomplikasi (Chobanian, 2004). Hal ini dapat dilihat dari prevalensi hipertensi nasional berdasarkan Riskesdas 2013 sebesar 25,8\%, tertinggi di Kepulauan Bangka Belitung (30,9\%), sedangkan terendah di Papua sebesar $(16,8 \%)$. Berdasarkan data tersebut dari $25,8 \%$ orang yang mengalami hipertensi hanya $1 / 3$ yang terdiagnosis, sisanya $2 / 3$ tidak terdiagnosis. Data menunjukkan hanya $0,7 \%$ orang yang terdiagnosis tekanan darah tinggi minum obat anti hipertensi. Hal ini menunjukkan bahwa sebagian besar penderita hipertensi tidak menyadari menderita hipertensi ataupun mendapatkan pengobatan (Kemenkes RI, 2017).

Data Dinas Kesehatan Provinsi Sulawesi Barat menunjukkan penyakit hipertensi mengalami peningkatan dari tahun ketahun, hal ini terlihat dari data yang diperoleh dari berbagai rumah sakit di Sulawesi Barat. Pada tahun 2013 penderita hipertensi sebanyak $30 \%$, tahun 2014 meningkat menjadi 37,6\%. Data Dinas Kesehatan Kabupaten Mamuju tahun 2013 menunjukkan penyakit hipertensi berada pada urutan ke 4 dari 10 penyakit terbanyak di Kabupaten Mamuju dengan jumlah kunjungan disarana kesehatan sebanyak 25.367, sedangkan pada tahun 2014 sebanyak 26.275 dantahun 2015 meningkat menjadi 27.445 (Bidang SP2TP Kab. Mamuju 2016). Data yang diperoleh di Puskesmas Rangas dalam tiga tahun terakhir juga menunjukkan peningkatan penderita hipertensi, tahun 2013 sebanyak $15,41 \%$, tahun 2014 sebanyak $23,8 \%$ dan tahun 2015 meningkat menjadi $25 \%$.

Hipertensi merupakan salah satu faktor risiko penyakit degeneratif antara lain penyakit jantung, stroke dan penyakit pembuluh darah lainnya, oleh sebab ituhipertensi harus dicegah dan diobati serta dikendalikan dengan baik. Kondisi patologis hipertensi memerlukan penanganan atau terapi baik farmakologis maupun nonfarmakologis (Copstead \& Banasik, 2005; Lewis, Heitkemper, \& Dirksen, 2000). Pada algoritma penanganan hipertensi, terapi nonfarmakologis termasuk modifikasi gaya hidup, pengelolaan stres, dan kecemasan, merupakan langkah awal yang harus dilakukan (Sudoyo, et al., 2006; Copstead \& Banasik, 2005; Lewis, Heitkemper \& Dirksen, 2000).

Terapi yang menggunakan transcendental meditation dan medical hypnosis secara nyata berdampak pada penurunan tekanan darah dan dapat digunakan sebagai terapi non farmakologis untuk membantu mengontrol tekanan darah (Stewart, 2005; GlickmanSimon, 2007). Salah satu intervensi yang menarik untuk dikaji adalah hipnosis. Hipnosis adalah suatu kondisi saat kesadaran menjadi menyempit karena pikiran yang sangat terkonsentrasi, sehingga hal di luar konsentrasi tersebut dapat diabaikan (Davis, Eshelman \& McKay, 1995). Penggunaan hipnosis di negara Indonesia sebagai terapi sudah dilakukan pada beberapa area, diantaranya di kebidanan, kedokteran gigi, anastesi psikiatri, dan psikologi. Hipnosis aman digunakan, 
mengurangi beban pembelian obat, dan efektif digunakan pada nyeri kronik apabila terapi konvensional sudah tidak efektif (Hammond, 2005).

Selain hipnosis terapi musik instrumen juga dapat menurunkan tekanan darah, melalui ritmik musik yang stabil dapat memberi irama teratur pada sistem kerja jantung dan menstimulasi kerja otak. Mendengarkan musik dengan harmoni yang baik akan menstimulasi otak untuk melakukan proses analisa terhadap lagu, meningkatkan imunitas tubuh, dan mempengaruhi sistem kerja hormon yang memberi keseimbangan pada detak jantung dan denyut nadi (Natalina, 2013). Penelitian yang dilakukan oleh Saing (2007) menyebutkan bahwa musik dapat menurunkan tekanan darah dan Afandi (2015) juga menyebutkanterapi musik instrumental classic dapat penurunan tekanan darah pada pasien stroke.

Kombinasi terapi musik instrumental dan self hyfnosis dirancang sebagai terapi dengan menggunakan kekuatan sugesti yang akan langsung merelaksasikan kondisi pasien, sehingga dapat menjadi lebih nyaman dalam waktu yang cukup singkat. dampak yang diharapkan adalah relaksai dan penurunan tekanan darah, meningkatkan pemulihan fisik, serta meringankan respon psikoemosional pasien.

\section{METODE PENELITIAN}

Penelitian ini merupakan pre eksperiment dengan rancangan one group pretest-posttest. populasi penelitian adalah pasien yang telah terdiagnosa hipertensidi Puskesmas Rangas Kabupaten Mamuju. Teknik pengambilan sampel menggunakan metode purposive sampling dengan kriteria: pasien hipertensi yang sudah tidak mendapatkan terapi farmakologi dari puskesmas, dapat ditemui pada saat kunjungan rumah, bersedia menandatangani informed consent. Jumlah sampel keseluruhan adalah 30 orang.
Variabel bebas dalam penelitian ini adalah kombinasi musik instrumental dan self hypnosis. terapi musik instrumental dan self hypnosis yang diberikan adalah rekaman musik instrumental dengan self hypnosis yang dimodifikasi oleh Henrikus (2014). Musik instrumental dan self hypnosis diberikan selama 13 menit 44 detik dalam satu kali pengukuran. Pengukuran tekanan darah dilakukan sebelum dan sesudah diberikan terapi musik instrumental dan self hypnosis. Variabel terikat adalah tekanan darah yang diukur menggunakan tensi meter ABN Regency ${ }^{\circledR}$ mercurial sphygmomanometer. terapi musik instrumental dan self hypnosisdiberikan 3 kali pertemuan dan tekanan darah diukur sebanyak 3 kali.

Analisis data dilakukan dengan analisis univariat dengan menampilkan distribusi dan persentase dari tiap variabel. Selanjutnya dilakukan analisis bivariat menggunakan $t$-test untuk mengetahui efektivitas terapi musik instrumental dan self hypnosis terhadap penurunan tekanan darah pada klien hipertensidengan tingkat kepercayaan 95\% ( $\alpha$ $0,05)$. Data dianalisis menggunakan program SPSS for windows version 16.

\section{HASIL PENELITIAN}

\section{Karakteristik responden}

Tabel 1. Distribusi frekuensi karakteristik responden

\begin{tabular}{lcc}
\hline $\begin{array}{l}\text { Karakteristi } \\
\text { k responden }\end{array}$ & $\mathbf{n = 3 0}$ & $\begin{array}{c}\text { Persentase } \\
(\boldsymbol{\%})\end{array}$ \\
\hline $\begin{array}{l}\text { Jenis } \\
\text { kelamin }\end{array}$ & 11 & 36,7 \\
Laki-laki & 19 & 63,3 \\
Perempuan & & \\
\hline Umur & & \\
$40-50$ & 4 & 13,3 \\
$51-60$ & 12 & 40,0 \\
$61-70$ & 11 & 36,7 \\
$71-80$ & 3 & 10,0 \\
\hline Pendidikan & & \\
SD & 20 & 66,6 \\
SMP & 5 & 16,7 \\
SMA & 5 & 16,7 \\
\hline
\end{tabular}




\begin{tabular}{lcc}
\hline Pekerjaan & & \\
Nelayan & 4 & 13,3 \\
Tani & 2 & 6,7 \\
URT & 16 & 53,3 \\
Wiraswasta & 8 & 26,7 \\
\hline
\end{tabular}

Tabel 1 menunjukkan jumlah responden yang paling banyak adalah berjenis kelamin perempuan 19 (63,3\%); umur responden terbanyak berumur 51-60 tahun 12 (40\%); pendidikan responden terbanyak SD 20 $(66,6 \%)$; pekerjaan responden terbanyak URT $16(53,3 \%)$

\section{Analisis Bivariat}

Menganalisis rata-rata tekanan darah sebelum dan sesudah terapi musik instrumental dan self hypnosis.

Tabel 2. Rerata \pm SD tekanan darah sistol sebelum dan sesudah dilakukan intervensi terapi musik instrumental dan self hypnosis. Tekanan Darah Nilai $p$ Sistol

\begin{tabular}{ccc}
\hline Pretest & $153 \pm 12.63$ & 0,0005 \\
Posttest & $144 \pm 12.15$ & \\
\hline
\end{tabular}

Tabel 2 menunjukkan ada perbedaan yang bermakna rerata tekanan darah sistol sebelum dan sesudah intervensi terapi musik instrumental dan self hypnosisdengan nilai $p=0,0005$

Tabel 3. Rerata \pm SD tekanan darah diastol sebelum dan sesudah dilakukan intervensi terapi musik instrumental dan self hypnosis

\begin{tabular}{ccc}
\hline & $\begin{array}{c}\text { Tekanan Darah } \\
\text { Diastol }\end{array}$ & Nilai $p$ \\
\hline Pretest & $94,67 \pm 5,45$ & 0 \\
Posttest & $89,56 \pm 6,69$ & 0,0005 \\
\hline
\end{tabular}

Tabel 3 menunjukkan ada perbedaan yang bermakna rerata tekanan darah sistol sebelum dan sesudah intervensi terapi musik instrumental dan self hypnosisdengan nilai $p=0,0005$

\section{PEMBAHASAN}

1. Karakteristik responden

Karakteristik responden berdasarkan jenis kelamin menunjukkan jenis kelamin terbanyak adalah perempuan. Jenis kelamin mempunyai pengaruh penting dalam regulasi tekanan darah. Sejumlah fakta menyatakan hormon sex mempengaruhi sistem renin angiotensin. Secara umum tekanan darah pada perempuan lebih tinggi dari pada laki-laki (Julius, 2008). Wolff (2006) juga menyatakan bahwa banyak orang terutama wanita menunjukkan peningkatan tekanan darah di atas 160 mmHg setelah mencapai usia 50 tahun. Kondisi yang berkaitan dengan usia ini bukanlah hipertensi sejati tetapi produk samping dari keausan arteriosklerosis dari arteri-arteri utama, terutama aorta, dan akibat dari berkurangnya kelenturan. Hal ini didukung oleh penelitian yang dilakukan oleh Sigarlaki (2006) yang mendapatkan hasil distribusi terbanyak penderita hipertensi berada pada kelompok umur 4556 tahun.

Berdasarkan umur menunjukkan bahwa umur >50 tahun lebih dominan mengalami hipertensi.Beberapa penelitian yang dilakukan, ternyata terbukti bahwa semakin tinggi umur seseorang maka semakin tinggi tekanan darahnya. Hal ini disebabkan elastisitas dinding pembuluh darah semakin menurun dengan bertambahnya umur. Sebelum umur55 tahun tekanan darah perempuan lebih tinggi dari pada laki-laki. Setelah umur 65 tahun tekanan darah pada laki-laki lebih tinggi dari pada perempuan. Dengan demikian, risiko hipertensi bertambah dengan semakin bertambahnya umur (Grayet al. 2005). Hal ini juga disebabkan karena elastisitas arteri akibat penuaan yang berhubungan dengan arterosklerosis (pengerasan dinding arteri) serta ketidakmampuan jaringan untuk memperbaiki diri atau mengganti kerusakan jaringan sehingga organ tubuh tidak bisa lagi mempertahankan fungsi normalnya dan tubuh tidak dapat bertahan terhadap infeksi dan memperbaiki kerusakan yang diderita. 
Hal ini sesuai dengan teori yang di kemukakan (Stanley, 2006) bahwa dengan meningkatnya usia, jantung dan pembuluh darah mengalami perubahan baik struktural maupun fungsional. Perubahan yang disebabkan oleh penuaan berlangsung lambat dan dengan awitan yang tidak disadari. Serta dari data yang didapatkan salah satu faktor pencetus terjadinya hipertensi yaitu karna keturunan (gen).

2. Kombinasi musik instrumental dan self hypnosis dapat menurunkan tekanan darah

Penanganan hipertensi dilakukan dengan dua cara yaitu secara farmakologis dan non farmakologis. Beberapa terapi non farmakologis yang dapat menurunkan tekanan darah melalui penelitian adalah terapi musik dan terapi relaksasi (Tim Terapi Musik, 2010). Beberapa penelitian mendapatkan musik akan membuat tubuh menjadi rileks, yang secara fisiologis manifestasinya dapat dilihat dari perubahan denyut jantung, tekanan darah dan tingkat kecemasan seseorang. Hal ini dibuktikan oleh Campbell (2002) bahwa musik bisa membantu penyembuhan penyakit-penyakit seperti: stress, kanker dan tekanan darah tinggi.

Hasil penelitian ini menunjukkan kombinasi musik instrumental dan self hypnosis dapat menurunkan tekanan darah sistol dan diastol klien hipertensi. Hasil penelitian ini diperkuat dari penelitian Saing (2007) dan Afandi (2015) bahwa mendengarkan musik dapat menurunkan tekanan darah dibandingkan dengan tidak mendengerkan musik.

Penelitian yang sama juga dilakukan Indah (2011) memperlihatkan bahwa dengan terapi musik instrumental mampu menurunkan tekanan darah sistolik dan diastolik. Hal ini sangat sejalan dengan penelitian ini yang juga didapatkan hasil adanya pengaruh terapi musik instrumental dan self hypnosis terhadap penurunan tekanan darah pada klien hipertensi di Puskesmas Rangas Kabupaten Mamuju

\section{SIMPULAN}

1. Kombinasi terapi musik instrumental dan self hypnosis efektif menurunkan tekanan darah sistolik pada klien hipertensi.

2. Kombinasi terapi musik instrumental dan self hypnosis efektif menurunkan tekanan darah diastolik pada klien hipertensi

\section{SARAN}

1. Klien

Lebih memperhatikan penyakitnya dan melanjutkan terapi musik instrumental dan self hypnosis atau terapi lainuntuk mempertahankan tekanan darah pada batas toleransi klien

\section{Instansi Pendidikan}

Terapi musik instrumental dan self hypnosisdapat digunakan sebagai referensi untuk penelitian lebih lanjut serta dapat diterapkan sebagai intervensi bagi mahasiswa dalam penanganan hipertensi saat praktek klinik. 


\section{DAFTAR PUSTAKA}

Afandi, A. (2015). Terapi musik instrumental classic: penurunan tekanan darah pada pasien stroke. The Sun. 2(2): 28-34

Campbell, D. G. (2002). Efek Mozart. Jakarta: Gramedia.

Chobanian, M.D. (2004). The Seventh Report of the Joint National Committee on Prevention, Detection, Evaluation, and Treatment of High Blood Pressure. U.S. Department Of Health And Human Services: NIH Publication.

Copstead, L.E.C., \& Banasik, J. L. (2005). Pathophysiology (3rd Ed.). St. Louis: Missouri Elsevier Saunders.

Davis, M., Eshelman, E.R., \& McKay, M. (1995). Panduan relaksasi \& reduksi stress (ed III) (A.Y.S. Hamid \& B.A. Keliat, penerjemah). Jakarta: EGC

Dinas Kesehatan Kabupaten Mamuju. (2015). Profil Dinas Kesehatan Kabupaten Maтuju Tahun 2015. Mamuju: Dinkes Kabupaten.

Glickman-Simon, R. (2007). Alternative treatments for hypertension. Diperoleh dari http://health library.epnet.com/print.aspx

Gray, H., Dawkins, K., Morgan, J., Simpson, I. (2005). Lecture Notes Kardiologi, Edisi empat. Jakarta: Erlangga.

Hammond, D.C. (2005). Clinical hypnosis and neurofeedback. Biofeedback, 33 (1), 1419.

Julius, S. (2008). Clinical Implications of Pathophysiologic Changes in theMidlife Universitas Sumatera Utara Hypertensive Patients. AmericanHeart Journal. 122: 886-891.

Kemenkes RI. (2013). Laporan nasional riset kesehatan dasar (Riskesdas). Jakarta: Kemenkes RI.

Kemenkes RI. (2017, Mei 17). Sebagian besar penderita hipertensi tidak menyadarinya. Retrieved April 7, 2018, from Kementerian Kesehatan Republik Indonesia: http:// www.depkes.go.id/article/view/1705180 0002/sebagian-besar-penderitahipertensi tidak -menyadarinya.html Lewis, S.M., Heitkemper, M.M, \& Dirksen, S.R. (2000). Medical surgical nursing assessment \&management of clinical problems (Vol 1). St. Louis: Mosby Inc.

Natalia, D. (2013).Terapi musik bidang keperawatan. Jakarta: Mitra Wacana Media.

Saing, S. K. (2007). Pengaruh musik klasik terhadap penurunan tekanan darah. Medan: FK-USU

Sigarlaki, H. (2006). Karakteristik dan faktor berhubungan dengan hipertensi di desa bocor, kecamatan bulus pesantren, kabupaten kebumen, jawa tengah tahun 2006. Jurnal Makara Kesehatan. 10(2).

Soenarta, A. A., Erwinanto, Mumpuni, A.S., Barack, R., Lukito, A. A., Hersunarti, N., Pratikto, R. S. (2015). Pedoman tatalaksana hipertensi pada penyakit kardiovaskuler. Edisi 1. Jakarta: PERKI

Stanley, M., \& Beare, P. G. (2006). Buku Ajar Keperawatan Gerontik. Jakarta: EGC.

Sudoyo, A.W., Setyohadi, B., Alwi, I., Simadibrata, M., \& Setiati, S. (2006). Buku ajar ilmu penyakit dalam jilid I (edisi IV). Jakarta: Pusat Penerbitan Departemen Ilmu Penyakit Dalam Fakultas Kedokteran Universitas Indonesia.

Tim terapi musik. (2010). Terapi musik untuk meancarkan peredaran darah diakses 24 Juni 2017 dari http://www.terapi musik.com

World Health Organization (WHO). (2012). Report of Hypertension. Geneva: WHO. 
Wolff, H. P. (2006). Hipertensi Cara

Mendeteksi dan Mencegah Tekanan

Darah Tinggi Sejak Dini. Jakarta: PT

Bhuana Ilmu Populer 